\title{
Barriers and Facilitators of Access to Maternal, Newborn and Child Health Services During the First Wave of COVID-19 Pandemic in Nigeria: Findings From a Qualitative Study
}

Godwin Otuodichinma Akaba ( $\square$ godwin.akaba@uniabuja.edu.ng)

University of Abuja College of Health Sciences https://orcid.org/0000-0002-8149-5492

Osasuyi Dirisu

Population Council

Kehinde S Okunade

University of Lagos College of Medicine

Eseoghene Adams

Research Hub Africa

Jane Ohioghame

LIFES WORTH RESEARCH LAB ॥

Obioma O Obikeze

FEDERAL MEDICAL CENTER BAYELSA

Emmanuel Izuka

University of Nigeria Teaching Hospital

Maryam Sulieman

MAHHAMED ABDULLAHI WASE TEACH HOSP

Emmanuel Edeh

GENERAL HOSPITAL,TAKUM,TARABA

\section{Research}

Keywords: COVID-19, maternal, newborn, child health, services, access, Nigeria

Posted Date: April 8th, 2021

DOI: https://doi.org/10.21203/rs.3.rs-398162/v1

License: @ (1) This work is licensed under a Creative Commons Attribution 4.0 International License. Read Full License 


\section{Abstract}

\section{Background}

Understanding how COVID-19 has shaped access to maternal. newborn and child health (MNCH) services in Nigeria and the contextual factors attributable to these changes is crucial towards development of policies and interventions that will assist the country in maintaining focus towards sustaining the little gains it has made over the past few years towards improving MNCH despite the COVID -19 pandemic.

The objective of the study was to explore the barriers and facilitators of access to MNCH services during the first wave of COVID-19 pandemic in Nigeria.

Methods

A qualitative study was conducted among different stakeholder groups in 18 public health facilities in Nigeria between May and July,2020. In-depth interviews were conducted among 54 study participants (service users, service providers and policymakers,) selected from across the three tiers of public health service delivery system in Nigeria (primary health centers, secondary health centers and tertiary health centers). Coding of the qualitative data and identification of themes from the transcripts were carried out and thematic approach was used for data analyses.

Results

Barriers to accessing MNCH services during the first wave of Covid-19 pandemic in Nigeria include fear of contracting COVID-19 infection at health facilities, transportation difficulties, movement restriction, stigmatization of sick persons, lack of personal protective equipment (PPE) /medical commodities, long waiting times at hospitals, shortage of manpower, lack of preparedness by health workers, and prioritization of essential services.

Enablers to access include the COVID-19 non-pharmacological measures instituted at the health facilities, community sensitization on healthcare access during the pandemic, and alternative strategies for administering immunization service at the clinics.

\section{Conclusion}

Access to $\mathrm{MNCH}$ services was negatively affected by the COVID-19 pandemic particularly due to challenges resulting from restrictions in movements and the health systems inability to provide enabling conditions for sustained utilization of $\mathrm{MNCH}$ services. There is need for national health managers and policy makers to institute measures that will allow unhindered access to $\mathrm{MNCH}$ services during future pandemics. This may include provision of socio-economic safety nets for women, provision of PPEs, use of e-health platforms for consultations, and incentives for health workers.

\section{Background}

On Jan 30,2020 the World Health Organization declared COVID-19 as a public health emergency of international concern. ${ }^{1}$ Nigeria's index case was confirmed on 27th February 2020 and the number has steadily risen to 
Nigeria alone disproportionately accounted for the highest number of maternal deaths $(67,000)$ in 2017 , thereby contributing up to $23 \%$ of global maternal deaths. ${ }^{3}$ Newborn and child health indices in Nigeria are also amongst the worst in the world. ${ }^{4}$ The poor maternal and newborn child health (MNCH) indices have been attributed to several factors including poor political will, weak health systems and lack of access to $\mathrm{MNCH}$ services. $^{5}$

Experiences from the Ebola Epidemic in West Africa showed that access to MNCH services is likely to be disrupted during public health crisis. ${ }^{6}$ With advent of COVID-19 pandemic, the resilience of health systems, their levels of emergency preparedness and the response of nations were tested and found to be fragile in most instances. ${ }^{7}$ This portends great danger for a country like Nigeria where access and utilization of maternal, newborn and child health services are still poor. ${ }^{8}$

COVID-19 pandemic may have affected the utilization of maternal and newborn child health services in Nigeria but the extent, directions, contextual factors at all the levels of health care service delivery as well as perceptions of patients, health workers and policymakers regarding these changes have not been evaluated in the same study in Nigeria. Additionally, the side effects of lockdown and movement restrictions instituted by the government to reduce community spread on maternal health in Nigeria have so far been largely unexplored.

The objective of this study was to explore the perceptions of service users, health workers and policy makers regarding barriers and facilitators of access to maternal, newborn child health services during the first wave of COVID-19 in Nigeria.

\section{Methods}

\section{Study Design}

The study utilized a qualitative study design to explore the perceptions of users of healthcare facilities, health workers, and policymakers on how COVID-19 has shaped the utilization of MNCH services as well as other contextual factors contributing to the projected views across six states of Nigeria.

\section{Study Settings}

The states were chosen purposefully to represent the six (6) geopolitical zones of the country. Three states namely Abuja, Lagos and Kano had high cases for COVID-19 while the other three (Enugu, Taraba and Bayelsa) had fewer cases of Covid-19. Three LGA were selected from each state and represented the three senatorial districts. The selection of states with high and few cases was considered necessary to explore contextual differences in barriers and facilitators to accessing $\mathrm{MNCH}$ services in these states. The states, health facilities and the number of covid-19 cases as of 17th May 2020 when data collection began is as shown in Table 1. 
Table 1

List of participating states and health facilities.

\begin{tabular}{|c|c|c|c|c|c|c|}
\hline \multirow{3}{*}{$\begin{array}{l}\text { Level of } \\
\text { health } \\
\text { facility }\end{array}$} & \multicolumn{3}{|c|}{$\begin{array}{l}\text { High COVID-19 burden states and number of cases } \\
\text { as of } 17 \text { th May, } 2020\end{array}$} & \multicolumn{3}{|c|}{$\begin{array}{l}\text { Low COVID-19 burden states and } \\
\text { number of cases as of 17th May,2020 }\end{array}$} \\
\hline & Abuja FCT & Lagos & Kano & Taraba & Enugu & Bayelsa \\
\hline & 397 & 2,373 & 844 & 17 & 11 & 6 \\
\hline $\begin{array}{l}\text { Tertiary } \\
\text { health } \\
\text { centre }\end{array}$ & $\begin{array}{l}\text { University of } \\
\text { Abuja } \\
\text { Teaching } \\
\text { Hospital, } \\
\text { Gwagwalada, } \\
\text { Abuja }\end{array}$ & $\begin{array}{l}\text { Lagos } \\
\text { University } \\
\text { Teaching } \\
\text { Hospital, Idi- } \\
\text { Araba, Lagos }\end{array}$ & $\begin{array}{l}\text { Muhammad } \\
\text { Abdullahi } \\
\text { Wase } \\
\text { Teaching } \\
\text { Hospital, } \\
\text { Kano }\end{array}$ & $\begin{array}{l}\text { Federal } \\
\text { Medical } \\
\text { Center } \\
\text { Jalingo, } \\
\text { Taraba }\end{array}$ & $\begin{array}{l}\text { University of } \\
\text { Nigeria } \\
\text { Teaching } \\
\text { Hospital, } \\
\text { Ituku-Ozalla, } \\
\text { Enugu }\end{array}$ & $\begin{array}{l}\text { Federal } \\
\text { Medical } \\
\text { Center, } \\
\text { Yenagoa }\end{array}$ \\
\hline $\begin{array}{l}\text { Secondary } \\
\text { health } \\
\text { centre }\end{array}$ & $\begin{array}{l}\text { General } \\
\text { Hospital, Kwali }\end{array}$ & $\begin{array}{l}\text { General } \\
\text { Hospital, } \\
\text { Badagry }\end{array}$ & $\begin{array}{l}\text { Wudil } \\
\text { General } \\
\text { Hospital, } \\
\text { Wudil }\end{array}$ & $\begin{array}{l}\text { General } \\
\text { Hospital, } \\
\text { Sunkani } \\
\text { Ardokola }\end{array}$ & $\begin{array}{l}\text { Poly General } \\
\text { Hospital, } \\
\text { Enugu, North } \\
\text { LGA }\end{array}$ & $\begin{array}{l}\text { Diete- } \\
\text { Koki } \\
\text { Memorial } \\
\text { Hospital, } \\
\text { Opolo }\end{array}$ \\
\hline $\begin{array}{l}\text { Primary } \\
\text { health } \\
\text { centre }\end{array}$ & $\begin{array}{l}\text { Comprehensive } \\
\text { Health Center, } \\
\text { Abaji }\end{array}$ & $\begin{array}{l}\text { Comprehensive } \\
\text { Health Center, } \\
\text { Isolo }\end{array}$ & $\begin{array}{l}\text { Comprehensi- } \\
\text { ve Health } \\
\text { Center, Kiru }\end{array}$ & $\begin{array}{l}\text { Rifkatu } \\
\text { Danjuma } \\
\text { maternity } \\
\text { PHC, } \\
\text { Takum }\end{array}$ & $\begin{array}{l}\text { Comprehensi- } \\
\text { ve Health } \\
\text { Center } \\
\text { Obukpa, } \\
\text { Nsukka }\end{array}$ & $\begin{array}{l}\text { Amarata } \\
\text { Primary } \\
\text { Health } \\
\text { Care } \\
\text { Center }\end{array}$ \\
\hline
\end{tabular}

\section{Study Participants and Data Collection Procedures}

A total of 54 in-depth interviews (IDIs) were conducted across all six (6) states with 9 interviews in each state comprising of 3 policymakers, 3 service providers and 3 service users. These were spread equally across the three levels of health care systems (Primary health care, secondary health care and tertiary healthcare) in the states. The state study coordinators scheduled and confirmed the dates and time of the planned IDIs with the study participants after obtaining informed written consent. The participants were also informed that the interview will be recorded during the informed consent process. Interviews were facilitated by trained interviewers either physically, over the phone or via ZOOM. The interviewers have expertise in the conduct of IDIs and worked with members of the core research team to schedule interviews with the respondents while determining the best time for the interview to take place. The study participants were informed about the purpose of the study and were invited to participate in the interview, which lasted for approximately 20 to 30 minutes. The interviews were conducted using an IDI guide designed specifically for each of the stakeholder groups as seen in the already published protocol. ${ }^{9}$

\section{Conceptual Framework (The Socio-ecological and three delays model)}

The conceptual framework for understanding the impact of COVID-19 on MNCH service utilization in this study was a hybrid of the socio-ecological model (SEM) and the three delays model. The SEM provides a theory-based approach to understanding the complex interaction between individual, interpersonal, community, institutional and policy factors that act as facilitators or barriers of uptake of $\mathrm{MNCH}$ services. In addition, it also facilitates the understanding of the complex and multifaceted interaction between a person and environmental factors that 
influence behaviour and practice. ${ }^{10}$ The delay model was used to explore delays in access to $\mathrm{MNCH}$ services in three phases. $^{11-13}$

\section{Socio-ecological Model}

- Individual Level: Socio-economic status, woman's perception of the risk involved in visiting the facility, perceived quality of care and physical health.

- Interpersonal Level: Family members/spousal support and attitude.

- Community Level: Road network, distance to health facility, availability of transportation, socio-cultural beliefs, attitudes of health care workers, perceived quality of care and provision of medical supplies.

\section{Three (3) Delays Model}

- Phase I Delay: Delay in deciding to seek care: These are individual or familial factors such as socio-cultural, economic factors, illness characteristics and perceived quality of care.

- Phase II Delay: Delay in reaching healthcare facility: This includes distance to health facilities, transport cost, availability of transportation and poor road networks.

- Phase III Delay: Delay in receiving adequate care at the health facility: This includes waiting/response time at the facility, shortage of supplies/equipment, the competence of available personnel, adequacy of the referral system and quality of care.

The intersection between the two models (socio-ecological model and three delay model) has been previously published in the research protocol for this study. ${ }^{13}$

\section{Data Analysis}

The interviews were recorded digitally, transcribed verbatim, and transferred to NVivo12 software for analysis. The codebook development process entailed a review of all the transcripts by three researchers who contributed to the development of a thematic framework of codes through consensus. Thematic analysis was used as an analytical strategy to explore patterns and themes within the data. Some codes were determined as priori codes and others emerged during the coding process. The process of identifying themes highlighted contextual situations that underpin perceptions and experiences expressed in the data. The themes were organized using the socio-economic and three (3) delay models to explore the contextual factors that shape utilization as well as enablers and barriers of access.

\section{Results}

Demographic characteristics of study participants are presented in Table 2. The results are presented under two major sections: Factors influencing access to $\mathrm{MNCH}$ services and factors influencing service delivery. The factors influencing access to $\mathrm{MNCH}$ services are broken down into three domains: delay in accessing care, delay in reaching care and delay in receiving care. Direct quotes from the interviews were used to illustrate the results at each level of delay. Majority of the services users were aged below 40 years reflecting the age category that utilizes MNCH services. Majority of the service providers were female, and nurses/doctors. Majority of policymakers were male (Table 2). 
Table 2

Participant's demographics

\begin{tabular}{|c|c|c|}
\hline \multicolumn{2}{|c|}{ DESCRIPTION } & Number of interviewees $(\mathrm{N}=54)$ \\
\hline \multicolumn{2}{|c|}{ Service Users (SU) } & 18 \\
\hline \multicolumn{2}{|c|}{ Service Providers (SP) } & 18 \\
\hline \multicolumn{2}{|c|}{ Policy Makers (PM) } & 18 \\
\hline \multicolumn{2}{|c|}{ Demographic features for service users } & Number of SUs ( $\mathrm{N}=18)$ \\
\hline \multirow[t]{3}{*}{ Age Group } & $20-30$ & 7 \\
\hline & $31-40$ & 10 \\
\hline & $41-50$ & 1 \\
\hline \multicolumn{2}{|c|}{ Demographic features for service providers } & Number of SPs $(\mathrm{N}=18)$ \\
\hline \multirow[t]{4}{*}{ Age Group } & $20-30$ & 1 \\
\hline & $31-40$ & 5 \\
\hline & $41-50$ & 5 \\
\hline & $51-60$ & 7 \\
\hline \multirow[t]{5}{*}{ Category } & CHEW & 1 \\
\hline & Matron/ Nursing Officers & 7 \\
\hline & Nurse-in-Charge & 4 \\
\hline & Resident Doctor/ Medical Officer & 3 \\
\hline & Consultants OBS/GYN & 3 \\
\hline \multirow[t]{2}{*}{ Gender } & Male & 4 \\
\hline & Female & 14 \\
\hline \multicolumn{2}{|c|}{ Demographic features for policymakers } & Number of PMs $(\mathrm{N}=18)$ \\
\hline \multirow[t]{3}{*}{ Age Group } & $30-40$ & 4 \\
\hline & $41-50$ & 11 \\
\hline & $51-60$ & 3 \\
\hline \multirow[t]{2}{*}{ Gender } & Male & 13 \\
\hline & Female & 5 \\
\hline
\end{tabular}

\section{Key themes and descriptions}

The key themes that emerged as barriers to access to MNCH services includes the following:

Socio-economic factors and fear of contracting COVID-19 at health facilities (delay in seeking care); transportation difficulties, movement restriction during the lockdown and harassment by security agents(Delay 
in reaching care); long waiting times and a daily capped number of patients to be attended to at the hospitals, patient's non-compliance with the" no- facemask, no entry" rules, inadequate PPEs, stigmatization of service users by health workers, shortage of manpower, lack of incentives and prioritization of essential services(Delay in receiving care).

This is shown in Table 3. 
Table 3

Key themes for barriers of access to $\mathrm{MNCH}$ services with supporting quotes

Determinants Themes/Description of key findings Supporting participant quote
of utilization
of $\mathrm{MNCH}$
services

\begin{tabular}{|c|c|c|}
\hline $\begin{array}{l}\text { Barriers to } \\
\text { access to } \\
\text { MNCH } \\
\text { services }\end{array}$ & \multirow{2}{*}{$\begin{array}{l}\text { Socio-economic factors. } \\
\text { Women could not go to the market to sell } \\
\text { their goods, there was paucity of funds to } \\
\text { pay for health services and high cost of } \\
\text { transportations which was difficult to get. }\end{array}$} & \multirow[t]{2}{*}{ 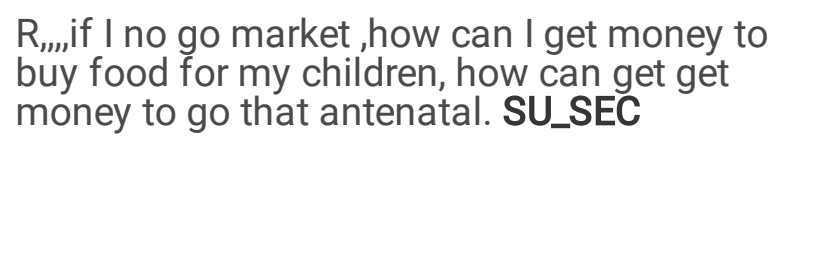 } \\
\hline \multirow{6}{*}{$\begin{array}{l}\text { Delay in } \\
\text { seeking care }\end{array}$} & & \\
\hline & $\begin{array}{l}\text { Fear of contracting COVID-19 at health } \\
\text { facilities }\end{array}$ & \multirow[t]{3}{*}{$\begin{array}{l}\text { R: ... People are afraid now to go to the } \\
\text { hospital... Because of fear of being infected by } \\
\text { the Covid... PM_SEC }\end{array}$} \\
\hline & $\begin{array}{l}\text { Health facilities were viewed as high-risk } \\
\text { centres for contracting COVID-19. }\end{array}$ & \\
\hline & $\begin{array}{l}\text { Service users were also concerned about } \\
\text { the availability of service providers to } \\
\text { attend to them at the facilities. }\end{array}$ & \\
\hline & Lack of transportation & \multirow{2}{*}{$\begin{array}{l}\text { R...Last week, I encountered a case of a } \\
\text { woman who missed ANC for so long. I say } \\
\text { aah" what's the problem? She said, I couldn't } \\
\text { get any transportation to come. }\end{array}$} \\
\hline & $\begin{array}{l}\text { Service users were reluctant to go to the } \\
\text { hospitals because there was no means of } \\
\text { transportations during the lockdown }\end{array}$ & \\
\hline \multirow[t]{2}{*}{$\begin{array}{l}\text { Delay in } \\
\text { reaching } \\
\text { health care } \\
\text { facility }\end{array}$} & $\begin{array}{l}\text { Movement restriction during the } \\
\text { lockdown and harassment by security } \\
\text { agents }\end{array}$ & \multirow[t]{2}{*}{$\begin{array}{l}\text { R...So, some of them have delay in getting to } \\
\text { the facility because of the restriction in } \\
\text { movement. SP_TERT }\end{array}$} \\
\hline & $\begin{array}{l}\text { There was a consensus among service } \\
\text { users and providers that checkpoints and } \\
\text { harassments from security personnel } \\
\text { created delays in access to services. }\end{array}$ & \\
\hline \multirow[t]{2}{*}{$\begin{array}{l}\text { Delay in } \\
\text { receiving } \\
\text { care at the } \\
\text { hospital }\end{array}$} & $\begin{array}{l}\text { Long waiting times and a daily capped } \\
\text { number of patients to be attended to at } \\
\text { the hospitals. }\end{array}$ & \multirow[t]{2}{*}{$\begin{array}{l}\text { R...You get to the hospital around } 7 \text { am, you'd } \\
\text { have to leave around } 12 \text { pm.I think the doctors } \\
\text { there are not enough, we'd have to sit and sit } \\
\text { and sit, you know. It's time consuming. SU_PRI }\end{array}$} \\
\hline & $\begin{array}{l}\text { Due to the measures that were instituted } \\
\text { to keep service users and providers safe } \\
\text { at the hospitals, waiting time at health } \\
\text { facilities increased. In addition, some } \\
\text { facilities reduced the number of health } \\
\text { personnel and capped the number of } \\
\text { patients to be seen daily. }\end{array}$ & \\
\hline
\end{tabular}




\section{Determinants of utilization \\ of $\mathrm{MNCH}$ \\ services \\ Themes/Description of key findings \\ Supporting participant quote}

Patient's non-compliance with the" nofacemask, no entry" rules

Patients without face masks were not attended to at the hospitals until they get one. This was usually expensive when bought from hawkers.

\section{Inadequate PPEs}

Lack of PPEs and medical commodities made it difficult to respond to patients on time as healthcare staff were afraid of getting infected by patients.

Stigmatization of service users by health workers

Service users were stigmatized by health workers once the patients have any symptom that may be associated with COVID-19 even when they do not have the disease.

Shortage of manpower, lack of incentives and prioritization of essential services.

Health workers were redistributed to the isolation centres especially at the tertiary hospitals which significantly reduced the number of providers. Services like obstetric emergencies were prioritized over ANC and immunization services at these sites.
R..Initially, when you ask them to use face mask, they will be telling you it's chocking them, we don't have the money to buy. PM_SEC
R: So over here...I have never....heard of personal protective equipment; I see them on the TV but no.. not even one has been provided for me here. Except about two months ago, they gave us $100 \mathrm{ml}$ of hand sanitizer...l bought a packet of mask at the cost of fourteen thousand naira. SP_PRI

R:I know of a woman who did not receive attention from health workers because she had cough and difficulty in breathing. They insisted that she must present a COVID-19 test result. At the end of the day, it was a case of cardiac failure in pregnancy, and she nearly died. SU_TERT

$\mathrm{R}$...these healthcare workers have to be there every day with no form of motivation or anything. Their feeding, accommodation is a problem because you have to think of the worries if they go back home to their families, wont they be infecting them? SU_SEC

\section{The key themes that emerged as facilitators of access to MNCH services includes the following:}

COVID-19 non-pharmacological measures instituted at the health facilities, community sensitization on healthcare access during the pandemic, adaptive strategies to reduce waiting time at health facilities, adaptation of service delivery structure and COVID-19 safety protocols and Training and supportive supervision for health workers. This is shown in Table 4. 
Table 4

Key themes for facilitators of access to $\mathrm{MNCH}$ services with supporting quotes

Themes/Description of key Supporting participant quote
findings

COVID-19 non-

pharmacological measures

instituted at the health

facilities.

These measures helped to allay the fears of patients on the possibility of getting infected with COVID-19 at the hospitals.

Community sensitization on healthcare access during the pandemic.

Some of these sensitization meetings involved community and religious leaders to improve service utilization among community members and inform them about preventive measures.

Adaptive strategies to reduce waiting time at health facilities.

Strategies included the suspension of general health talks during ANC and immunization services an d long appointments for low risk women at clinics.

Adaptation of service delivery structure and COVID-19 safety protocols

The protocols included guidance on the use of PPEs (face mask, gloves), temperature checks as well as ensuring the service provider and service user compliance to safety measures.
R: So, wherever we go before they even check your BP, they would sanitize the BP equipment. When you enter inside their clinics you will wash your hands and they provide you with sanitizers to sanitize your hands. They provide all these for the patients. SU_TERT
R: Okay at our setting, like in the primary health care, immediately we..be early April, we had already called for a meeting at the FCT public health department and agreed we should start community sensitization amongst the religious leaders, policy makers and traditional leaders. PM_PRI
. R: It is not somehow difficult because they won't waste our time. If we just come, those of us who will not be seen to are requested to come back on a later date while they will ask others to wait. They also give us longer appointment days. So it is not difficult, it is easy. SU_SEC
R: Each time we see a patient we sanitize our hands, you must wear your gloves, you know we take all the necessary precautions. You know...so we did our best. PM_PRI 


\section{Themes/Description of key Supporting participant quote findings}

Training and supportive supervision for health workers

This was mainly at the primary health centers. Health workers were trained on how to reorganize the clinics and units to care for patients during the pandemic.

\section{Barriers to access to $\mathrm{MNCH}$ services}

$\mathrm{R}$ :We have trainings, and all of us, all the health workers including those that are cleaners, we have been retrained and they know about hand hygiene, respiratory hygiene, the face mask and social distance, even the way we see patients is not as before where people have to seat anyhow..we have nurses and some community health extension workers that work under the $\mathrm{MNCH}$, they are trained specialist to even carry out their activities even with this issue of COVID. PM_SEC

\section{Delay in seeking care}

Several factors influenced the decision making of women to visit health facilities and access MNCH services during the COVID-19 pandemic.

1. Socio-economic factors

Decision making around care-seeking was influenced by socio-economic drivers of utilization. Petty trading was the means of livelihood of women in most communities; during the nationwide COVID - 19 lockdown, majority of these women were unable to sell their products and did not have disposable funds to pay for MNCH services. The consequence of this was the inability of women to afford $\mathrm{MNCH}$ services at facilities. The increased cost of transportation during the lockdown period and the associated cost of procuring personal protective equipment (PPEs) like face masks required to visit clinics constrained the capacity of users to access care.

$R$ : because they are poor, even the face mask some of them couldn't afford the face mask because for days they've not gone out they couldn't go to the market, there was no sale, there was no movement even the transport was very expensive so that's really a very important factor-PM_PRI

\section{Fear of contracting COVID-19 at health facilities}

The fear of contracting COVID-19 at the facilities were key barriers to access to MNCH services during the lockdown. Health facilities were viewed as high-risk centers for contracting COVID-19 as it was widely publicized that health workers were contracting the virus. Service users were also concerned about the availability of service providers to attend to them at the facilities as there was limited information about the availability of health services during the lockdown. Religious beliefs that the COVID-19 situation required divine intervention was also a barrier that kept potential service users from accessing health facilities during this period.

R: Yes, I was anxious when he just started little fever. How can I even be able to access the health facility because how will I even go to the health facility? What am I going to do there? Would there be health personnel to attend to me? And when I get there, won't I be infected? - SU_TERT

Delay in reaching care

1. Transportation difficulties 
Service users experienced significant delays in reaching health facilities due to transportation difficulties. The number of transportation service providers significantly reduced during the lockdown. Potential service users who had their vehicles found it easier to visit the hospitals than those who were dependent on public transportation. Public transportation became more expensive and difficult to access especially in remote or rural areas and some people had to resort to walking to facilities to access care.

R: The delay in getting to hospital that's the major problem. That was the major problem then, before the ambulance could go round to pick people. Actually, that was the major problem during the lockdown, accessibility to the hospital. We the workers couldn't get to the hospital on time -SP_SEC

R: Transportation for example, if you want to get to a health facility, you need to be able to move, means of transportation, everybody was locked down so there is no how you can easily get to health facilities, if you don't have it in the house, the public transportation system are down during the time of the lock-down, so people may have to necessarily maybe trek to the nearest health facilities to attend it or be able to... if you have means of moving, personal means of transportation to be able to get to where you can acquire those services, those were the challenges I was talking about. - PM_TERT

1. Movement restriction during the lockdown and harassment by security agents

During the lockdown, in addition to the restriction of movement, there was a curfew in place. Security agents were positioned on the road at checkpoints to enforce the lockdown. There was a consensus among service users and providers that these checkpoints created delays in reaching the hospitals. There were reported cases of security agencies harassing commuters and requesting for proof that they were going to the hospital in some instances. The experience with security agents varied as some service users, mentioned that although there were delays at checkpoints, they could continue their journey after they presented their hospital identity cards or medication they were previously given at the hospital.

R: The lockdown affected everybody. Once you have your facemask and you tell them (security agents) you're heading to the hospital, and you have any evidence as in any card to show them they will believe it. Then they'll allow you to pass but apart from that, if you just tell them you're heading to hospital, they will not allow you but once you insist, they'll rather take you there by themselves. Yes, the last time I was sick, the last time, that was exactly what they did to us, I was telling them that my baby was sick (laughter). Yes, but my baby was not feeling fine, they refused because that was my first time. They had to take us there by themselves and I said it's even better it's like they know I don't have enough money to pay the bike man. They had to take me there by themselves and we see the doctor and we left, so while coming back still that the same road. I had to show them the medicine collected there so that was how they allowed me now. - SU_SEC

\section{Delay in receiving care}

1. Long waiting times and a daily capped number of patients to be attended to at the hospitals.

Due to the measures that were instituted to keep service users and providers safe at the hospitals, waiting time at health facilities increased. In addition, some facilities reduced the number of health personnel attending to patients and this resulted in further delays in receiving care. Health facilities capped the number of services users receiving care daily and when the number of patients seeking care exceeded the allotted number, they were

Page $12 / 21$ 
turned back and asked to return on a later date. This implied that service users had to visit the facilities very early to be included in the list of patients to be seen each day; this increased waiting time and some service users waited and did not get attended to. Additionally, this was said to have resulted in poor quality of care received by service users.

$R$ : we wanted to stick to the twenty patients per day, because of social distancing and we wanted to avoid overcrowding so we only attend to twenty clients daily. yes, twenty per day, we run our services Monday to Fridays, so we ask them to come in their twenties so most of the time we have more than twenty and we have to turn back others, so it's been a problem. PM_PRI

2. Patients' non-compliance with the "no- facemask, no entry" rules

Some service providers reported that when patients presented to the health facilities without facemasks, they were declined treatment, and this caused significant delays in receiving care in instances where these patients could not afford to buy facemasks. Service providers felt vulnerable and at risk of contracting COVID-19 if they provided services to patients who did not wear masks. The hospitals were unable to provide face masks for patients who were made to buy them at very high costs from hawkers at the hospitals. Service users corroborated this and reported that they experienced significant delays due to non-use of face masks. Some reasons given by service users for not wearing facemasks was they could not afford to buy facemasks, and they felt a chocking sensation when they wore the masks.

R: Two weeks ago there was a patient that had ectopic (pregnancy), she collapsed while in the market so it was with the intervention of the COVID-19 committee in the hospital that she was brought in as they made a made case for her that this is not a COVID-19 but a gynae emergency... The instruction from the state is that no face mask no entry, so it has really been difficult to really assess patients that need our services once they cannot afford the hundred naira face mask, they turn them out, they can't enter the hospital. PM_SEC

\section{Inadequate PPEs and Medical Commodities}

There was a consensus among policymakers and service providers that the inadequacy of PPEs affected the capacity of health facilities to respond effectively to the pandemic and maintain optimal service delivery levels. Some service providers had to purchase PPEs with personal funds to ensure they were safe and could continue delivering health services. In other instances, patients were asked to buy PPEs as part of the service delivery process. Policymakers, especially those at primary healthcare facilities, reported that PPEs were only procured for health facilities at the initial phase of the pandemic. Subsequently, the government was unresponsive to their pleas to provide more PPEs. The only PPEs that were made available were facemasks and hand gloves; facilities were not provided with face shields, gowns, and boots. The lack of information or protocols to guide the response of healthcare workers to the COVID-19 pandemic and safely continue service delivery made it more difficult for service providers.

R: The biggest challenge was the absence of personal protective equipment, and lack of information because the facility was not given direct, first-hand information, and so we were... scouting for information by ourselves on the web, on the internet, looking for information for yourself, there was no action plan, there was no protocol, everyone was just you know scrambling to do things for yourself as you can, there was obviously no personal

Page $13 / 21$ 
protective equipment provided, so people had to use their monies... to buy these things for themselves, to protect themselves, and there was just total lack of leadership - SP_TERT

\section{Stigmatization of service users by health workers}

Service users were stigmatized by health workers once the patients have any symptom that may be associated with COVID-19 even when they do not have the disease. The lack of testing capacity in the hospitals worsened these problems as patients were refused care in the hospitals until they presented COVID-19 test results.

R: Before now, in fact everything was like 0\%, people are afraid to come to the health facility. Health workers would not want to be in their primary place of assignment for fear of Covid 19, somebody will present with malaria symptoms, 'eeh this is COVID-19 oo' the next thing will be for them to run to their houses, Patients with symptoms are stigmatized. But we have to continue to educate them that no, it's not every person you see on the street or any symptoms that are similar to Covid-19 that is Covid 19... - PM_PRI

\section{Shortage of manpower, lack of incentives and prioritization of essential services.}

Majority of the tertiary facilities experienced a significant shortage of health personnel because these staff also doubled as health care providers at the various isolation centres. Health managers in some facilities were instructed to reduce the number of health personnel involved in the response during the lockdown and this resulted in an increased workload for health workers responding to the healthcare crisis. This increased workload resulted in delays in the delivery of $\mathrm{MNCH}$ services. No additional incentives were provided for the healthcare workers who had to run extra shifts during the pandemic. This significantly affected the staff motivation and impacted on welfare of health workers who were afraid to return home in between shifts to avoid infecting their families. A policymaker reported that health workers would have been better motivated if incentives were provided to support on-site accommodation and a daily allowance during the lockdown.

R: That time they declared lockdown, an order came from our parent hospital, that we should cut down manpower either to sixty percent... which we did... That means that if every morning, we were having up to ten nurses on morning duty... during the pandemic we reduced to five. -SP_PRI

R: That one is something that we have been battling with... but even before COVID you know that manpower is never enough especially in a setting like this because the workload here is very very tasking because we have many patients. What we see is that other centers refer their patients here, so we work... work is actually tasking here, and staff are never enough, you know but we manage - SP_TERT

\section{Facilitators of access to MNCH services}

1. COVID-19 non-pharmacological measures instituted at the health facilities.

Some service users opined that the good hygiene practices and precautionary measures observed at health facilities encouraged them to access care and allayed their fears about contracting COVID-19 at the facilities. In addition, the health education they received at the facilities was useful in clarifying misconceptions they had about COVID-19 transmission and facilitating access to $\mathrm{MNCH}$ services. 
R: Initially when we had not been lectured on how the thing spread, we thought if you come outside immediately you will be contaminated, so that is why we stayed in the house. Even the time we were supposed to go and register for $A N C$, we thought that the hospitals would not be working, but when we reached there, they opened our eyes, they lectured us on some certain things, so the fear now... the fear we had initially was no longer there now. - SU_SEC

2. Community sensitization on healthcare access during the pandemic

Factors that positively influenced utilization of $\mathrm{MNCH}$ services as reported by policy makers include communitylevel COVID-19 sensitization. Some of these sensitization meetings involved community and religious leaders to improve service utilization among community members. In addition, febrile illnesses such as malaria which could be easily treated were perceived as COVID-19; the sensitization sessions enlightened community members about the different scenarios and the need to seek appropriate care. Community sensitization was also useful in communicating to patients on the need to wear face masks as well as cost-effective ways of obtaining and using facemasks.

$R$ : Yes, access to services is really a problem, with the significant advocacy, consistent engagement with our stake holders, the front-line health care workers, I think we have been able to see a little improvement in utilization of services. - PM_PRI

R: Actually, the level of adherence is steady, because we see them when they go, when they are coming the next time, we see them what you tell them they are adhering to, initially when you ask them to use face mask, they will be telling you its chocking them, we don't have the money to buy, but when you explain to them these are the rational on how you use this face mask, some of them they even use plain clothes and sew it to wear it to cover their nose and mouth, it also helps them, by educating them, they actually adhere to it. - PM_SEC

3. Adaptive strategies to reduce waiting time at health facilities.

Some health facilities adapted to the challenges with service delivery during the pandemic by staggering ANC appointments and scheduling patients' attendance to the hospital for treatment. Patients were encouraged to visit these facilities because they knew the health workers were committed to ensuring that they received care.

R: Right now, just as I told you, in the health talk, we use to tell them about personal and environmental hygiene and even err... their antenatal days, we are trying to shift it. No longer the regular schedules we were using. For instance, we can tell somebody to come in three weeks when ordinarily she is supposed to come in two weeks, you understand, so we now provide longer intervals between visits. For instance, come in one month, come in two month and that is the directive of the government. They say we should be telling them like that because if they come and they become crowded, you will not be able to provide the covid-19 safety measures. So, we now gap their visit so that they don't come very close as we use to give them before. - SP_SEC

Adaptation of service delivery structure and COVID-19 safety protocols

Majority of policy makers and service providers reported that the service delivery structure was reorganized to be responsive to the demands of the lockdown period. In some facilities, $\mathrm{MNCH}$ care which was previously delivered to service users using a batched system on specific days was adapted to occur on a rolling basis. This implied that MNCH service users who visited these facilities for ANC and immunization services were attended 
to immediately they arrived at the facility. This was done to reduce large gatherings of service users at the facilities and improve social distancing. Health facilities also reduced the number of caregivers who accompanied MNCH service users to the facilities to limit large gatherings. Some facilities also instituted protocols for ANC visits, home visits for postnatal care and delivery. The protocols included guidance on the use of PPEs (face mask, gloves), temperature checks as well as ensuring the service provider and service user compliance to safety measures. Temperature checks were carried out at the gates before any service user or service provider was granted access to the health facility as well as handwashing and use of hand sanitizers. A policymaker mentioned that there were special arrangements for pregnant women who tested positive to Covid19.

R: Any patient on admission has only one patient relative to stay with him and the nurse in charge has to know who the person is. You don't just keep changing people for us. PM_SEC

R: Even those that delivered during this period, after 6 hours of post-delivery, we watch them and if they're stable, we discharge them home, because the more they stay in the hospital, visitors will tend to come and visit them. -

\section{SP_PRI}

R: So essentially, all these things are present it's just that the place is not as busy because we decreased hospital visits because for women for instance there's a time of their gestation that they're meant to come every two weeks... we increased some of them to four weeks... until a particular time. Those who are meant to be coming every week, we increased it to two weeks if they're low risk; meaning low risk means they don't have problems that we think that can get complicated you know, so we give such women a longer appointment so it makes the clinic lighter; so that the social and physical distancing can be practiced in clinic... So you know if you give them that long appointment time it will improve our physical distancing, so that makes the clinic a bit lighter. -

\section{SP_TERT}

Training and supportive supervision for health workers

Training and supportive supervision were provided for health workers and community volunteers on COVID-19 protocols, the preparedness of the health workers, use of PPEs and managing of suspected cases. Training of trainers' sessions not only focused on COVID-19 but also on the care of women and children at the primary health care centers.

R: We had training of trainers... for health workers at the primary health care level in the communities...Society of Gynaecology and Obstetrics of Nigeria (SOGON) was represented, so many other organizations that are in the care for women and children were also represented at the meeting... we trained our health workers just for four days on COVID-19 response, preparedness of the health workers towards the COVID-19 pandemic. So, we taught them how to use PPE, the ones we must use always and the ones we use for a suspected case. We also had training of community volunteers. So that they will go to the communities... because you know rumors are causing panic amongst the community members which is now preventing them from accessing appropriate care or even notifying appropriately when we have suspected cases in the community... we finished the training last week but there will be ongoing supportive supervision. - PM_PRI

R: okay, we have an infection prevention control at the health facility so prior to that we have had series of trainings so we had two trainings on infection prevention control and we decided to paste and give some IEC 
materials on infection which were displayed at different places in the facility, so the PPEs like I said earlier on at the beginning it was regular but towards the end erm is not end yet we are still in it and it sometimes there is always paucity of supply, it can about six weeks to get a new supply - PM_PRI

\section{Discussion}

This paper reports the perceptions and experiences of key stakeholders across the three levels of health systems in Nigeria on barriers and facilitators associated with access to $\mathrm{MNCH}$ services during the first six months of COVID-19 pandemic. It also explored other contextual issues that have shaped service delivery along the $\mathrm{MNCH}$ continuum of care during the COVID-19 pandemic.

Barriers to accessing MNCH services by patients in this study included fear of contracting COVID-19 at health facilities, lack of funds to pay for services at the health facilities, transportation difficulties, shortage of manpower, long waiting times and a daily capped number of patients to be attended to at the hospitals, negative attitude of healthcare workers, harassment by security agents, and stigmatization of service users by health workers.

A previous study that assessed the psychological impact of covid-19 amongst pregnant women in Italy had reported women's concerns and anxiety regarding possibility of transmission of the disease to their babies. ${ }^{14}$ This is also consistent with reports from a national survey in the United Kingdom ${ }^{15}$ and another study from India ${ }^{16}$ in which pregnant women were unwilling to seek maternity care at the hospital due to fear of the risk of coronavirus transmission to them or their babies. The delay in seeking care by pregnant women due to fear of getting infected with COVID-19 could lead to increased home deliveries with attendant complications. In a study by Davis et al, ${ }^{17}$ it was found that women in New York, USA are preferring home deliveries instead of institutional deliveries due to the fear of being infected at the hospital.

Sustained health education of the public on the modes of transmission of any novel disease of public health importance as well as measures put in place at the hospitals to forestall transmission to patients would be useful in allaying fears, myths, and misconceptions. Unfortunately, the information presented to the Nigerian public by health workers on non-availability of personal protective equipment and the increasing number of deaths from COVID-18 amongst health workers strengthened patients resolve to stay away from the hospitals.

Lockdown is an effective measure in slowing the spread of coronavirus around the globe ${ }^{18}$ and was implemented in several countries including Nigeria to reduce community spread of COVID-19. Previous literatures have highlighted the challenges posed by the lock down especially as it relates to socio-economic losses. ${ }^{19}$ Our study identified an indirect linkage between lock down and lack of access to MNCH services as patients could not afford to pay for health care costs or even transport costs to reach the hospitals due to halt of economic activities. A previous study on the impact of COVID-19 on health services utilization in Nepal also reported the negative implication of lockdown on access to $\mathrm{MNCH}$ services. ${ }^{20}$ Drawing from these experiences, it may be wise to suggest the need for provision of social safety nets to cushion economic difficulties as well as allow free movement of pregnant women during any future lockdown.

Healthcare workers rely on personal protective equipment to protect themselves and their patients from being infected and infecting others. Our study showed that health workers in Nigeria lacked PPEs for the care and 
management of patients. This resulted in lack of confidence, low morale, and unwillingness of the health workers to provide services for fear of being exposed to COVID-19. Semaan and colleagues ${ }^{21}$ also reported a similar perception by health workers. The World Health Organization in recognition of the universal shortage of PPEs during the period of this study had recommended its rationale use which involved using of PPEs based on the risk of exposure (e.g., type of activity) and the transmission dynamics of the pathogen (e.g., contact, droplet, or aerosol). ${ }^{22}$

A major problem that hampered health workers willingness to easily offer maternity services was the lack of incentives and health insurance policy for staff who felt that it was too risky "putting their lives on the line" when there were no life insurance policies for them. One of the participants had reported that hazard allowance for health workers was five thousand naira per month (US\$13.2/month: Central bank of Nigeria exchange rate). Although, the hazard allowance of health workers in Lagos state which had the highest number of cases of COVID-19 during the study period witnessed an increase from US\$13 to US\$65 to incentivize them., ${ }^{23}$ there is still need for an overhaul of the current policy towards improving health workers moral for efficient service delivery during pandemics. Participants in this study revealed that stigmatization of patients by health workers was an important factor which discouraged pregnant women from seeking MNCH services. COVID-19 was regarded at as a death sentence" during the initial period of the pandemic and as such health workers discriminated against any body who had symptoms similar to COVID-19. This was compounded by the lack of knowledge regarding COVID-19 and inadequacy of PPEs which made critical assessment difficult.

The highlighted challenges in this study faced by service users and providers in accessing and delivering $\mathrm{MNCH}$ services respectively during the COVID-19 pandemic closely resembles the problems identified during Ebola virus outbreaks in three West African countries. ${ }^{6}$ This suggests that disease outbreaks and pandemics impacts on $\mathrm{MNCH}$ services in similar patterns. Therefore, concerted efforts need to be made to address the identified problems towards sustaining $\mathrm{MNCH}$ services during pandemics.

Despite the barriers, our study identified facilitators of access to and delivery of MNCH services during the first six months of COVID-19 pandemic in Nigeria. These facilitators should be further improved upon towards increased service delivery after the COVID-19 pandemics. These include the need for continued community education regarding the disease, modification of health care consultation practices, training, and supportive supervision of health workers regarding safe practices during disease outbreaks and adaptation of available guidelines and protocols for uninterrupted service delivery.

The strength of the study was the involvement of three stakeholder groups (service users, health care workers and policy makers). This allowed for examination of the subject matter from various perspectives. Additionally, participants were drawn from the six geopolitical zones of the country, three geopolitical zones of the states and across the three levels of Nigeria's public health service system. This provided a nationally representative group for generalizability of the study findings. This study was however limited by the fact that most of the interviews was conducted using the phone which limited assessment of nonverbal cues which are important aspects of qualitative studies.

It is envisaged that the scientific evidence generated from this study will be used for the development of policies and interventions that will assist Nigeria in maintaining focus towards improving maternal and newborn child health amidst the COVID-19 pandemic. This can be achieved by addressing underlying reasons for non- 
utilization of $\mathrm{MNCH}$ services during infectious disease outbreaks and ensure prioritization of sustenance of MNCH services by early community sensitization to allay fears, provision of social safety nets to cushion economic difficulties, special transportation arrangements and incentives for health workers, training of health workers and provision of PPEs for patients and health workers safety.

\section{Conclusion}

Access to MNCH services were negatively affected by the COVID-19 pandemic particularly due to challenges resulting from restrictions in movements and the health systems inability to provide enabling conditions for sustained utilization of $\mathrm{MNCH}$ services. There is need for national health managers and policy makers to institute measures that will allow unhindered access to $\mathrm{MNCH}$ services during future pandemics.

\section{Abbreviations}

In-depth interviews -IDIs

MNCH- Maternal, newborn and child health

PPE-Personal protective equipment

Service Providers -SP

Service Users- SU

Socio-ecological model -SEM

Policy Makers -PM

\section{Declarations}

Ethical approval and consent to participate Ethics approvals were obtained from the Health Research Ethics Committee of the participating tertiary hospitals involved in the study: University of Abuja Teaching Hospital (UATH/HREC/PR/2020/001), Lagos University Teaching Hospital (LUTHHREC/EREV/0520/42), University of Nigeria Teaching Hospital, Enugu (NHREC/05/01/2008B-FWA00002458-1RB00002323), Mohammad Abdullahi Wase Teaching Hospital, Kano (MOH/Off/797/T.I/2060), Federal Medical Centre, Yenagoa, Bayelsa (FMC/ADM/017/Vol.1/138) and Federal Medical Centre, Jalingo, Taraba (FMC/JL/ADM/330).All participants provided written informed consents. Consent for publication Not applicable. Availability of data and materials The data sets generated during and/or analyzed during the current study are available from the corresponding author on reasonable request. Competing interests The authors have no competing interests to declare. Funding Not applicable. Authors Contributions GOA was principal investigator and coordinated the research activities related to this study. GOA and OD conceptualized the study. GOA, OD, KSO, ES, JO, OOO, EI, MS, ME were involved in the design of the study and data collection. Data analysis was by OD, ES, JO, GOA and data interpretation was by GOA, OD, KSO, ES, JO, OOO, El, MS, ME. GOA, OD and KSO wrote the original manuscript draft and was contributed to by all authors. The final manuscript was reviewed and approved by all the authors. 
Acknowledgements The authors wish to acknowledge the stakeholders who made inputs in the design or participated in the qualitative study.

\section{References}

1. World Health Organization (2020). Statement on the second meeting of the International Health Regulations (2005) Emergency Committee regarding the outbreak of novel coronavirus (COVID-19). January 30, 2020. https://www.who.int/news/item/30-01-2020-statement-on-the-second-meeting-of-the-international-healthregulations-(2005)-emergency-committee-regarding-the-outbreak-of-novel-coronavirus-(2019-ncov). Accessed June 10, 2020.

2. Nigeria Centre for Disease Control (NCDC). Covid-19 Daily report. Available at: https://covid19.ncdc.gov.ng/report/. Accessed 16/03/2021

3. World Health Organization (2019). Trends in maternal mortality 2000 to 2017: estimates by WHO, UNICEF, UNFPA, World Bank Group and the United Nations Population Division: executive summary. World Health Organization. https://apps.who.int/iris/handle/10665/327596. Accessed on August 2, 2020.

4. Lawn JE, Blencowe H, Waiswa P, Amouzou A, Mathers C, Hogan D, et al. Stillbirths: rates, risk factors, and acceleration towards 2030. Lancet. 2016; 387(10018): 587-603.

5. Uneke CJ, Sombie I, Uro-Chukwu HC, Johnson E. Developing equity-focused interventions for maternal and child health in Nigeria: an evidence synthesis for policy, based on equitable impact sensitive tool (EQUIST). Pan Afr Med J. 2019; 34: 158.

6. Yerger P, Jalloh M, Coltart CEM, Karina K. Barriers to maternal health services during the Ebola outbreak in three West African countries: a literature review. BMJ Global Health 2020; 5: e002974.

7. El Bcheraoui, C., Weishaar, H., Pozo-Martin, F. et al. Assessing COVID-19 through the lens of health systems' preparedness: time for a change. Global Health 16, 112 (2020). https://doi.org/10.1186/s12992-020-006455

8. National Population Commission (NPC) [Nigeria] and ICF. Nigeria Demographic and Health Survey (NDHS) 2018. Abuja, Nigeria, and Rockville, Maryland, USA: NPC and ICF.

9. Akaba G, Dirisu O, Okunade K, Adams E, Ohioghame J, Obikeze O, et al. Impact of COVID-19 on utilization of maternal, newborn and child health services in Nigeria: protocol for a country-level mixed-methods study. F1000Research 2020, 9:1106.

10. Heise LL. Violence against women: an integrated, ecological framework. Violence Against Women. 1998; 4(3): 262-90.

11. Thaddeus S, Maine D. Too far to walk : maternal mortality in context. Soc Sci Med. 1994; 38(8): $1091-110$.

12. Combs Thorsen V, Sundby J, Malata A. Piecing together the maternal death puzzle through narratives: the three delays model revisited. PLoS One. 2012; 7(12): e52090.

13. Mgawadere F, Unkels R, Kazembe A, van den Broek N. Factors associated with maternal mortality in Malawi: application of the three delays model. BMC Pregnancy and Childbirth 2017; 17(1): 1-9.

14. Saccone G, Florio A, Aiello F, Venturella R, De Angelis MC, Locci M, et al. Psychological impact of coronavirus disease 2019 in pregnant women. Am. J. Obstet. Gynecol. 2020;

S0002937820305275.DOI: https://doi.org/10.1016/j.ajog.2020.05.003

Page 20/21 
15. Karavadra, B., Stockl, A., Prosser-Snelling, E. et al. Women's perceptions of COVID-19 and their healthcare experiences: a qualitative thematic analysis of a national survey of pregnant women in the United Kingdom. BMC Pregnancy Childbirth. 2020; 20: 600 https://doi.org/10.1186/s12884-020-03283-2.

16. Goyal M, Singh P, Singh K, Shekhar S, Agrawal N, Misra S. The effect of COVID-19 pandemic on maternal health due to delay in seeking health care: experience from a tertiary center. Int J Gynaecol Obstet.2020;152(2):231-235.

17. Davis-Floyd R, Gutschow K, Schwartz DA. Pregnancy, birth and the COVID-19 pandemic in the United States. Med Anthropol. 2020; 39(5): 413- 427.

18. Flaxman S, Mishra S, Gandy A, Unwin HJT, Mellan TA, Coupland H et al. Estimating the effects of nonpharmaceutical interventions on COVID-19 in Europe. 2020 ; 584(7820):257-261.

19. Poudel K, Subedi P. Impact of COVID-19 pandemic on socioeconomic and mental health aspects in Nepal. Int J Soc Psychiatry. 2020 Dec;66(8):748-755. doi:10.1177/0020764020942247.

20. Singh DR, Sunuwar DR, Shah SK, Karki K,Sah LK, Adhikan B et al. Impact of COVID-19 on health services utilization in Province-2 of Nepal: a qualitative study among community members and stakeholders. BMC Health Serv Res.2021; 21:174. doi: 1186/s12913-021-06176-y

21. Semaan A, Audet C, Huysmans E, Afolabi B, Assarag B, Banke-Thomas A et al. Voices from the frontline: findings from a thematic analysis of a rapid online global survey of maternal and newborn health professionals facing the COVID-19 pandemic. BMJ Glob Health. 2020 Jun;5(6):e002967. doi: 10.1136/bmjgh-2020-002967.

22. World Health Organization. Rational use of personal protective equipment for coronavirus disease 2019 (COVID-19), 2020. Available at: https://apps.who.int/iris/bitstream/handle/10665/331215/ WHO-2019nCov-IPCPPE_use-2020.1-eng.pdf.

23. Oyadiran OT, Agaga LA, Adebisi YA, Lucero-Prisno D. Nigeria, COVID-19 and the dearth of health workers. J Glob Health.2020;10(2):020379. 